\title{
Economic Natural Selection: What Concept of Selection?
}

\section{Jean Gayon}

\section{Biological Theory}

ISSN 1555-5542

Volume 6

Number 4

Biol Theory (2012) 6:320-325

DOI 10.1007/s13752-012-0042-6

\section{Biological Theory}

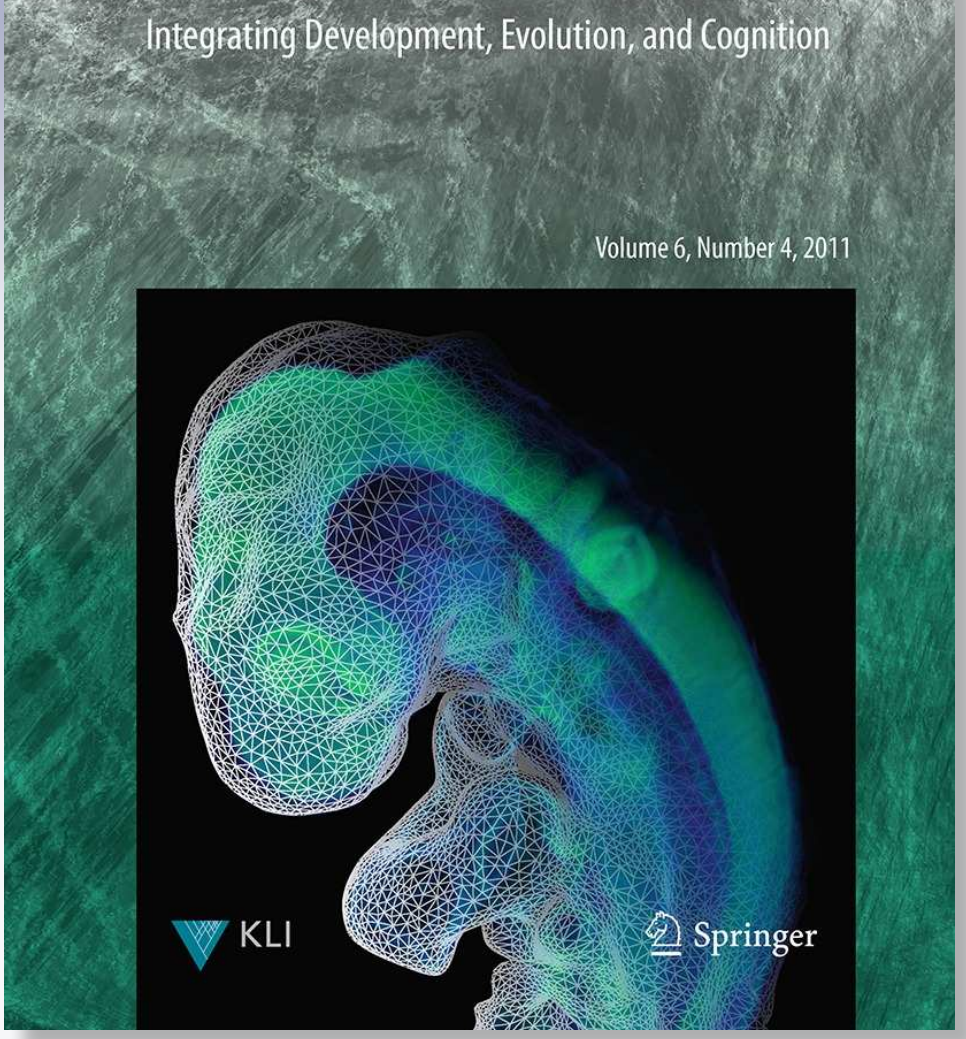

\section{鱼 Springer}


Your article is protected by copyright and all rights are held exclusively by Konrad Lorenz Institute for Evolution and Cognitive Research. This e-offprint is for personal use only and shall not be self-archived in electronic repositories. If you wish to selfarchive your work, please use the accepted author's version for posting to your own website or your institution's repository. You may further deposit the accepted author's version on a funder's repository at a funder's request, provided it is not made publicly available until 12 months after publication. 


\title{
Economic Natural Selection: What Concept of Selection?
}

\author{
Jean Gayon
}

Received: 4 October 2011/Accepted: 13 March 2012/Published online: 6 November 2012

(C) Konrad Lorenz Institute for Evolution and Cognition Research 2012

\begin{abstract}
The article examines two cases of adoption of evolutionary ways of thinking by modern economists: Nelson and Winter's (Evolutionary Theory of Economic Change, 1982), and evolutionary game theory (1990s and after). In both cases, the authors explicitly refer to natural selection in an economic context. I show that natural selection is taken in two different senses, which correspond to two general conceptions of the principle of natural selection, one of which contains reproduction and heredity as key elements, whereas the other does not.
\end{abstract}

Keywords Evolutionary economics - Evolutionary game theory (EGT)Heredity · Multiplication · Natural selection . Richard R. Nelson · Reproduction · Bernard Walliser . Sidney G. Winter

Since Darwin, and even before, an impressive list of concepts and models has been exchanged in both directions between economics and evolutionary theory. In the present article, I dwell upon two modern cases of adoption of evolutionary ways of thinking by economists: one is Nelson and Winter's Evolutionary Theory of Economic Change (1982), which introduced the notion of "economic natural selection"; the other and more recent case is evolutionary game theory (EGT henceforth) applied to the solution of some particular economic problems. In both cases, natural selection is understood in the sense of the genetic theory of natural selection, and is invoked in the

J. Gayon $(\bowtie)$

Institut d'Histoire et de Philosophie des Sciences et des Techniques (IHPST), Université Paris 1-Panthéon Sorbonne, Paris, France

e-mail: jean.gayon@gmail.com context of microeconomics (i.e., the part of economics that considers the decisions made at a low level, e.g., individuals or firms).

In order to assess what is imported from evolutionary theory into economic theory, we need to identify the generalized formulations of the principle of natural selection that are applied in economics. I will therefore begin by defining two kinds of generalization of the principle of natural selection. I will then examine, first, the evolutionary theory of economic change developed by Nelson and Winter (N\&W henceforth), and, second, the use of EGT in present economic theory, which rely upon different concepts of natural selection.

\section{Generalization of the Principle of Natural Selection}

Since 1970, several attempts to generalize the concept of natural selection have been made. These fall into two categories (Gayon 2009b): in the first, reproduction and heredity are a crucial component; in the second, they are not.

Richard Lewontin (1970) has explored the first possibility. He proposed generalizing Darwin's natural selection through a formulation that avoids referring to any particular level of organization. Natural selection is defined as a process arising from the existence of populations of entities that share three properties: phenotypic variation, differential fitness, and heritability of fitness. In comparison with traditional "Darwinian" formulations of natural selection, this formulation is more general in two senses. First, Lewontin's characterization does not involve the Malthusian dimension of overpopulation: "The element of competition between organisms for a resource in short supply is not integral to the argument" (Lewontin 1970, p. 1). Second, 
his formulation does not refer to any particular mechanism of inheritance, but only to "a correlation in fitness between parent and offspring." This correlation can operate between traits or entities of any sort, at any level of organization, provided that there is some idea of descent. Lewontin claims that heritability of fitness applies to cytoplasmic inheritance, populations, species, and even culturally transmissible items. Thus, "the generality of the principles of natural selection means that any entities in nature that have variation, reproduction, and heritability may evolve" (p. 1). This attempt to generalize the principle of natural selection has been widely applied in a number of domains, both within and outside biology. In biology, it has been applied to genes, somatic cells (e.g., in development and cancer), populations, species, monophyletic taxa, and, even, as suggested by Lewontin himself, biotic communities. But it has also been applied to artificial life, computer science, exobiology, and cultural evolution. Any other attempt to generalize natural selection that would also admit that the natural selection requires the existence of a "parent-progeny" or "ancestor-descendant" relationship would fall in this first method of generalization of natural selection. For instance, Price's equation shares this property. Although Price's characterization of natural selection is more formal and abstract, it belongs, I think, to the same kind of generalization (Price 1972; see Okasha's 2007 illuminating comments). Karl Pearson's biometric characterization in his poorly known "Fundamental theorem in natural selection" might also be mentioned here (Pearson 1886, §10a; see Gayon 1998).

This first generalization of natural selection requires entities that either reproduce or are replicated. The second consists in relaxing Lewontin's conditions of reproduction and heredity. As far as I know, this proposal was first formulated by ecologists (see, e.g., Van Valen 1991; Blandin 2007), and subsequently by some philosophers (Rosenberg and Bouchard 2004; Bouchard 2007, 2008). These authors have asserted that ecosystems or other ecological entities, e.g., symbiotic individuals, can evolve in spite of their inability to reproduce as such. Some sort of natural selection can nevertheless occur on these entities: what is maximized is the survival and persistence of the entity considered. No heredity in the traditional sense is required, only persistence or continuity. For this kind of generalization of natural selection, neither Maynard Smith's notion of "multiplication" (Maynard Smith 1988) nor Szathmáry and Maynard Smith's (1997) notion of "reproducer," nor even James Griesemer's notion of progeneration (a process leading to an increase of individuals of the same kind) seems a necessary condition. All these ways of "deprivileging genes" (Griesemer 2000a, b) propose to generalize the concepts of replication and/or reproduction by referring to some sort of "persistence through successive life-cycles," or "re- occurrence," or even just "return" of something. But this is precisely the point: ecosystems, although they may split, can also-and do indeed-emerge without one having to refer to any sort of repetition or re-occurrence; material continuity with a former entity of the same sort is not a necessary condition of their existence. The case of symbiotic organisms implying recurrent migration of an organism (e.g., a bacterium) into another organism (e.g., a squid; Bouchard's favorite example) is a bit more complicated: here we do observe the re-occurrence of something in a system endowed with material continuity. I do not want to go further in this kind of problem here. Enough to say that some ecologists (and some economists, as we will see shortly) have endorsed a concept of natural selection exclusively founded upon differential persistence, without reference to any kind of replicative or reproductive process. ${ }^{1}$

The two generalizations of the principle of natural selection that I have delineated here are incompatible when taken as the basis for a definition of natural selection. One cannot simultaneously say that reproduction and heredity are necessary conditions for natural selection to exist, and that they are not (this raises difficult theoretical problems that I will not discuss here). Furthermore, the second generalization-the ecological concept of natural selection-is more general than the first, which requires reproduction and heritability of some type of entity. My objective here is to show that these two possible definitions of natural selection are valuable tools for assessing the kinds of analogies involved in contemporary evolutionary approaches to economics, which I turn to now.

\section{"Economic Natural Selection": Nelson and Winter's Evolutionary Theory of Economic Change}

The origins of N\&W's "evolutionary theory of economic change" go back to the 1960s, but it was only in 1982 that these two authors published a book under that title. I base my discussion here on this book and on a useful article by Nelson (1994), which makes the analogies between evolution and economics more explicit. ${ }^{2}$

$\mathrm{N} \& \mathrm{~W}$ propose nothing less than an alternative to the neoclassical theory of microeconomics. Neoclassical theory claims that economic agents behave as utility-maximizing rational agents. Other authors before $\mathrm{N} \& \mathrm{~W}$ had criticized

\footnotetext{
${ }^{1}$ A rather harsh debate ensued about whether such an ecological concept of natural selection is useful. Lewontin (1970, 2009), for instance, has expressed serious doubts: without reproduction and heritability, there is only a process of differential elimination, not an indefinite and open process of transformation.

${ }^{2}$ Except in the last few years, evolutionary economics has been neglected by philosophers of biology. See, however, Callebaut (1983), Rosenberg (1994); Gayon (1999, 2009a).
} 
the limits of this assumption. As early as 1950, Alchian underlined that economic agents are in fact often ill informed, that they act in a context of uncertainty, and that their actions are quite often non-rational with respect to their objectives. Consequently, Alchian proposed that economists take into account two dimensions that they had traditionally neglected - the cognitive aspect of agents' decision making, and the dynamic of their interactions - and not only attempt to describe the equilibrium they attain. Following Alchian, some economists began thinking about the possibility of revising economic theory with the help of concepts imported from evolutionary biology, especially Darwinian evolutionary biology. Evolutionary theory, they hoped, would foster the development of an economic theory more open to the dynamics of interaction among agents, and less dependent upon a strict concept of their rationality.

$\mathrm{N} \& \mathrm{~W}$ were a product of this new approach to economic theory. What distinguished them was the project of offering a radical alternative to the traditional neoclassical view. They proposed to rebuild economic theory around the idea that the behavior of firms is at any given time determined by a definite number of capacities and rules of decision, which exhibit a relative continuity within the firm. These capacities and rules are technological or managerial competences, and recurrent strategies for investment and research and development. All of them constitute "routines," which are the basic unit of economic analysis. Routines are transmitted within the firm, and they are gradually modified in time. The ability of firms to adapt their routines to their environment-rather than their existence as profit-maximizing agents-is the ultimate factor in their success or decline.

This point deserves emphasis. For classical theory, firms' use of routines at all levels results from their profitmaximizing strategy. For the evolutionary theory of economic change, the order of causation is reversed: routines endogenously determine firms' behavior. The idea is that firms have an "organizational memory." At any given time, the current routines determine the subsequent state of the enterprise-whence the massive use of a Markovian approach by N\&W (1982, p. 19).

Another distinctive trait of N\&W's approach is their careful analogy between biological natural selection and what they call "economic natural selection" (ENS). ENS is not properly a selection of firms (as in previous works), but a selection of routines, which then determines the survival or extinction of firms. N\&W-and especially Nelsonhave elaborated a careful comparison between ENS and genetic selection. Economic natural selection requires taking into account three kinds of entities:

(1) Firms that correspond to individual organisms in biological evolution.
(2) Routines that correspond to genes: they are "heritable" and "mutable." Here, however, we should be cautious about what $\mathrm{N} \& \mathrm{~W}$ say: routines are "heritable" in the sense that a given firm has an "organizational memory," which the authors conceive of as the partial continuity of a combination of routines. This is a rather problematic point in the theory, for two reasons: (a) there is no room for reproduction; routines are "transmitted" within the firm; (b) N\&W distinguish routines proper (analogs to genes) and "coadapted routines" (analogs to genotypes), which constitute as such the "organizational memory" of the firm (Nelson 1994).

(3) The firms compete within a population of firms occupying a given "environment," viz., the market for a certain kind of product. Consequently, firms have different fitness values, by which the authors mean that there are "patterns of survival and differential growth among a population of firms." Note here that N\&W speak of the "growth" of firms, not of the reproduction of anything. Firms survive and persist; they do not reproduce. Routines also enjoy survival for as long as they persist, but they are not replicated either through the "reproduction" of firms (making a daughter firm or division-vertical inheritance) or in the sense of horizontal transfer from firm to firm (horizontal inheritance).

These analogies being mooted, the evolutionary theory of economic change consists in saying that there exists a strong economic analog of natural selection in biology: routines that are beneficial to the firms are selected within a population of firms, in a given economic environment. This is "economic natural selection."

We observe here a major case of transfer of concepts from one domain to another. However, we must be precise about what $\mathrm{N} \& \mathrm{~W}$ are really doing. Reading their book and articles, it is clear that $\mathrm{N} \& \mathrm{~W}$ do not transpose models of selection from population genetics to economic theory. Their models are genuinely economic models, inspired by traditional microeconomic models. In fact, as I will show later, these are models of behavioral learning. Thus, what $\mathrm{N} \& \mathrm{~W}$ transfer from biology is not a set of models, but a set of concepts.

Because my purpose is to evaluate an analogy, I would like now to point out a difficulty of this theoretical construction. The problem is the absence of any precise economic analog of reproduction. While I say that this is a difficulty, the authors do not see it as such, but rather as an intrinsic feature of their conception. For them, routines are not passed on through a process of reproduction of firms. If routines are "heritable," they are not inherited via the reproduction of firms. Firms exhibit varying patterns of "survival and differential growth," but their fitness is not based upon differential reproduction. 
For this reason, N\&W refuse to consider their economic theory as a case of cultural evolution. For them the "heritability" of routines does not mean that they are passed on from individual to individual by imitation. In particular, they do not describe a horizontal transmission of routines from firm to firm (or, more precisely, they do not consider such transfer as causally important). Routines are transmitted within the firm. What this means is that technological and managerial innovation result from complex forms of organization that characterize the firm as a whole. The "heritability" of routines therefore boils down to what the authors call "organizational memory." We thus have a case of "behavioral learning," rather than a case of blind evolution through the selection of cultural items-routines (Walliser 2000). This behavioral learning is handled by the firm itself, which acts as an autonomous collective agent adjusting the aggregate of "routines" according to its observable environment ( $\&$ W 1982, p. 18). This is the reason why $\mathrm{N} \& \mathrm{~W}$ say that their theory is ultimately as much "Lamarckian" as it is "Darwinian":

$\ldots$ it is neither difficult nor implausible to develop models of firm behavior that interweave "blind" and "deliberate" processes.... Our theory is unabashedly Lamarckian: it contemplates both the "inheritance" of acquired characteristics and the timely appearance of variation under the stimulus of adversity. (p. 11)

In conclusion, $\mathrm{N} \& \mathrm{~W}$ 's notion of economic natural selection makes sense in view of the second generalization of the principle of natural selection I defined earlier. In spite of their insistent reference to the language of population genetics, N\&W's notion of economic natural selection is not compatible with any definition of natural selection that depends on a reproductive process of any sort. The theory of economic natural selection relies rather on an ecological concept of selection, where the heritability of traits is admitted only insofar as it refers to the continuity of certain behaviors within a given system (the firm). Routines are not selected as such among firms: they are adjustable variables within a firm that tries to improve its adaptation to its own environment according to what it has learnt by trial and error.

\section{Evolutionary Game Theory and Economics}

N\&W's evolutionary theory of economic change represents an attempt to rebuild microeconomic theory as a whole. I argue that it relies upon a concept of natural selection that does not require reproducing entities. I will now consider another evolutionary approach to economic theory, consistent with the other generalization of natural selection that I characterized above, which postulates the existence of self-reproducing entities.
Here I will draw upon a classification of the methods currently used in economics for describing the interactions between economic agents, which I borrow from the French economist Bernard Walliser (1994, 1998). Walliser defines four different approaches of economic interactions between economic agents, based upon the cognitive abilities attributed to these agents.

(1) Eductive approach. This approach postulates that agents are endowed with strong rationality. Each agent is able to perfectly simulate the behavior of other agents and to understand the functioning of the system as a whole. ${ }^{3}$ In such a situation, mutual beliefs converge towards a (Nash) equilibrium. Such agents are guided by a "Lewisian hand."

(2) Cognitive learning likewise relies upon the notion of optimizing agents; but the rationality of these agents is weakened in that they revise their imperfect beliefs about their environment according to what they observe. Their actions result not only from a trialand-error process; they also deliberately explore their context and anticipate events (second-order learning). Their beliefs are locally rational, and may also lead conjointly to a Nash equilibrium. Such agents are guided by a "Bayesian hand."

(3) Behavioral learning. In this case, agents' behavior depends directly on the observable environment. What determines the behaviors are the rewards or failures they experience. In certain cases this can lead to optimal actions, which, again, may conjointly result in a Nash equilibrium. However, the equilibrium attained is mainly determined by a trial-and-error process. Agents are guided by a "Skinnerian hand."

(4) Evolutionary approach. In this approach,

agents are pure automata, endowed with a rigid function of behavior. These agents meet randomly in pairs and reproduce according to the utilities that they obtain. Subjected to a process of selection, they are

\footnotetext{
3 This is why this approach is said to be "eductive." "Eductive" contrasts with "adaptive." An eductive approach postulates that rational agents, following a reasoning process, can deduce that an equilibrium should occur. The time necessary for a real agent to come to this conclusion is not taken into account. Adaptive learning operates in real time..

4 This is an allusion to the philosopher David Lewis (1941-2001). In his book Convention (1969), Lewis makes use of the notion of "common knowledge." An example of common knowledge would be that everyone knows $p$, and everyone knows that everyone knows p. Walliser's expression "Lewisian hand" refers to an equilibrium guided by the existence of a common knowledge. If economic agents adjust their behavior through learning, their behavior may converge to something "rational" in the economist's sense of the word, as a result of the "common knowledge" that they come to share.
} 
guided by a "Darwinian hand." Utility amounts to fitness, so that only one homogeneous class of agents may sometimes survive. When a given class cannot be invaded by another one ..., an evolutionary stable equilibrium is attained. This equilibrium is close to a symmetrical Nash equilibrium. (Walliser 1994, pp. 53-54; my translation)

Walliser's account would probably be endorsed by a number of economists today. Let me underline some striking features of this classification. (1) From the first to the last approach, we move from a postulate of perfect knowledge to a total absence of agent's beliefs. (2) The four methods rely upon a formal treatment of economics in terms of game theory: the four strategies may lead to a Nash equilibrium, or something close to it. ${ }^{5}$ This means that a certain number of economic problems can be solved equally well by any of the four strategies. (3) This classification assumes a particular interpretation of the word "evolutionary": an evolutionary method is a method founded upon an application to economics of John Maynard Smith's notion of evolutionarily stable strategies. The kind of Darwinism involved here is certainly not the same as in N\&W's evolutionary theory of economic change examined earlier.

Walliser alludes to the incorporation of EGT into economics, an important shift in economic theory (on EGT generally, see Maynard Smith 1982; McKenzie 2009; on EGT as applied in economic theory, see Binmore and Samuelson 1991; Lesourne et al. 2002). In this approach, the parallel between the genetic theory of natural selection and evolutionary economics is more rigorous than in N\&W's case. The notion of the gene (or rather of hereditary material) is transposed under the form of a strategy followed by a class of actors; these strategies are selected as such, because the claim is that strategies replicate through imitation. This is a big difference from N\&W's approach, where the most elementary level, the "routine," is absorbed into the upper level of the "organizational memory" of the firm. Consequently, the notion of natural selection used here fits well with the first generalization of natural selection that I defined at the beginning of this article: a notion of selection applying to entities "that have variation, reproduction, and heritability" (Lewontin 1970, p. 1).

This explains why those who adhere to this approach think N\&W's evolutionary economics is not really "evolutionary." According to Walliser (1994), N\&W's theory is in reality a version of the "behavioral learning" approach. It is not "evolutionary" ("Darwinian") because it does not treat economic agents as automata, and does not recognize

\footnotetext{
5 In simple terms, a group of players is in a Nash equilibrium if each one is making the best decision that he or she can, taking into account the decisions of the others.
}

a specific level where something is clearly replicated. Rather, the kind of learning involved in N\&W is "behavioral learning" rather than "cognitive learning," because N\&W's Markovian perspective relates to their conviction that economic agents (firms) behave according to immediate successes and failures in their own environment.

\section{Conclusions}

(1) The two important examples of evolutionary approaches to economic theory analyzed here fall into two categories that fit well with the two ways of generalizing the principle of natural selection that I have characterized. N\&W's evolutionary economics relies on an ecological concept of natural selection in which reproduction or replication play no crucial role, and which takes heredity in the loosest sense of the "organizational memory" of the actors. EGT applied to economics relies on a more orthodox representation of natural selection, where heredity is taken in the ordinary sense of traits passed on from one generation to the next through some process of replication. EGT fits well with the commonest kind of generalization of natural selection, implying a strong concept of "heredity" relying on the reproduction of one or another kind of entity.

(2) From a strictly economic point of view, the two approaches correspond to different treatments of the interactions between economic agents. N\&W's evolutionary theory of economic change is in fact an example of "behavioral learning." Only EGT can be said to be genuinely "evolutionary." Not only is the analogy with Darwinian evolutionary theory reasonably rigorous from a conceptual point of view; it relies also on a transposition of population genetics models into economics.

(3) For all that, one cannot say that the analogy between economics and evolution is loose in one case, and perfectly clear in the other case. This depends on one's frame of reference. If one takes the genetical theory of natural selection as a reference frame, then (in spite of what $\mathrm{N} \& \mathrm{~W}$ say) EGT is certainly closer to a strong analogy than N\&W's scheme. But the analogy used by economic EGT is not that explicit. The idea of replication of a strategy through imitation is understandable, but the mechanisms of selection are unclear. Especially, it is questionable whether economic agents are really deprived of all knowledge and beliefs, and act just as automata moved by a compulsive strategy. (For a detailed analysis of the subtle relation between learning and evolution in economic theory, see Walliser 2011). 
(4) Another big difference between N\&W's approach and EGT is their ambition. Whereas $\mathrm{N} \& \mathrm{~W}$ intended to stake out a general alternative to the neoclassical theory of economics, contemporary economists who appeal to EGT and selection do not believe that this is the ultimate framework of economic theory. They take it as a useful tool for solving certain kinds of problems, in certain circumstances, and with a clear awareness of the degree of simplification and idealization that their models imply. For instance, EGT is useful for modeling processes of contagion (e.g., convergence of a market on a new product). It is also useful for deep theoretical problems, such as the evolution of cooperation. But in all cases, the attitude is pragmatic, a matter of inventing ingenious models, rather than rebuilding the theoretical framework of modern economics wholesale.

Acknowledgments I thank Abigail Lustig for her fruitful comments and careful linguistic revision of this paper, which would not be what it is without her help. Thanks also to the anonymous reviewer for her fruitful comments and queries.

\section{References}

Alchian A (1950) Uncertainty, evolution, and economic theory. J Pol Econ 58:211-221

Binmore K, Samuelson L (1991) Evolutionary stability in repeated games played by finite automata. J Econ Theory 57:278-305

Blandin P (2007) L'écosystème existe-t-il? Le tout et la partie en écologie. In: Martin $\mathrm{T}$ (ed) Le tout et les parties dans les systèmes naturels. Vuibert, Paris, pp 21-46

Bouchard F (2007) Évolution d'écosystèmes sans réduction à la fitness des parties. In: Martin T (ed) Le tout et les parties dans les systèmes naturels. Vuibert, Paris, pp 57-64

Bouchard F (2008) Causal processes, fitness, and the differential persistence of lineages. Philos Sci 7:560-570

Callebaut W (1983) Contribution to a general theory of rationality on evolutionary foundations, with an application to the organization of scientific knowledge (in Dutch). PhD Thesis, Department of Philosophy and Moral Science, Ghent University, Belgium

Gayon J (1998) Darwinism's struggle for survival: heredity and the hypothesis of natural selection. Cambridge University Press, Cambridge

Gayon J (1999) Sélection naturelle biologique et sélection naturelle économique: examen d'une analogie. Économies et Sociétés 35:107-126

Gayon J (2009a) De l'économie à la biologie et retour: la sélection naturelle. In: Martin T (ed) L'unité des sciences aujourd'hui. Vuibert, Paris, pp 13-25
Gayon J (2009b) Actualité du darwinisme. Bull Soc Fr Philos 103:1-47

Griesemer J (2000a) Reproduction and the reduction of genetics. In: Beurton P, Falk R, Rheinberger HJ (eds) The concept of the gene in development and evolution: Historical and epistemological perspectives. Cambridge University Press, Cambridge, pp 240-285

Griesemer J (2000b) Development, culture, and the units of inheritance. Phil Sci 67:S348-S368

Lesourne J, Orléan A, Walliser B (2002) Leçons de microéconomie évolutionniste. Odile Jacob, Paris. (English: Evolutionary microeconomics, Springer, Berlin, 2006)

Lewis D (1969) Convention. Harvard University Press, Cambridge

Lewontin RC (1970) The units of selection. Ann Rev Ecol Syst $1: 1-18$

Lewontin RC (2009) Postface. In: Martin T, Huneman P, Lecointre G, Silberstein $M$ (eds), Les mondes darwiniens: l'évolution de l'évolution. Syllepses, Paris, pp 1076-1080

Maynard Smith J (1982) Evolution and the theory of games. Cambridge University Press, Cambridge

Maynard Smith J (1988) Evolutionary progress and the levels of selection. In: Nitecki M (ed) Evolutionary progress. University of Chicago Press, Chicago, pp 219-230

Maynard Smith J, Szathmáry E (1997) From replicators to reproducers: the first major transitions leading to life. J Theor Biol 187:555-572

McKenzie AJ (2009) Evolutionary game theory. In: Zalta EN (ed) Stanford encyclopedia of philosophy, Fall 2010 edn. http://plato.stanford.edu/entries/game-evolutionary/. Accessed 1 July 2012

Nelson RR (1994) Evolutionary theorizing about economic change. In: Smelser N, Swedberg R (eds) Economic sociology. Princeton University Press, Princeton, pp 8-36

Nelson RR, Winter SG (1982) An evolutionary theory of economic change. Belknap Press of Harvard University Press, Cambridge

Okasha S (2007) Cultural inheritance and Fisher's "fundamental theorem" of natural selection. Biol Theory 2:290-299

Pearson K (1886) Mathematical contributions to the theory of evolution. III. Regression, heredity and panmixia. Philos Trans R Soc Lond A 187:253-318

Price GR (1972) Extension of covariance selection mathematics. Ann Hum Genet 35:485-490

Rosenberg A (1994) Does evolutionary theory give comfort or inspiration to economics? In: Mirowski P (ed) Natural images in economic thought. Cambridge University Press, Cambridge, pp 384-407

Rosenberg A, Bouchard F (2004) Fitness, probability and the principles of natural selection. Br J Philos Sci 55:693-712

Van Valen L (1991) Biotal evolution: a manifesto. Evol Theory 10:1-13

Walliser B (1994) L'intelligence de l'économie. Odile Jacob, Paris

Walliser B (1998) A spectrum of equilibration processes in game theory. J Evol Econ 8:67-87

Walliser B (2000) L'économie cognitive. Odile Jacob, Paris. (English: Cognitive economics, Springer, Berlin 2008)

Walliser B (2011) Learning versus evolution: from biology to game theory. Biol Theory. doi:10.1007/s13752-012-0071-1 